\title{
Mobile-Based Self-Care Application for COVID-19: Development Process Using the ADDIE Model
}

\author{
Hamid Reza SAEIDNIA ${ }^{\mathrm{a}}$, Marcel AUSLOOS ${ }^{\mathrm{b}}$, Zahra MOHAMMADZADEH ${ }^{\mathrm{c}}$, \\ Afshin BABAJANI ${ }^{\mathrm{a}}$ and Mohammad HASSANZADHH ${ }^{\mathrm{a}, 1}$ \\ a Department of Knowledge and Information Science, Tarbiat Modares University \\ (TMU), Tehran, Iran \\ ${ }^{\mathrm{b}}$ Department of Statistics and Econometrics, Bucharest University of Economic \\ Studies, Bucharest, Romania \\ ${ }^{\mathrm{c}}$ Department of Health Information Technology, Kashan University of Medical \\ Sciences and Health Services, Kashan, Iran
}

\begin{abstract}
During the COVID-19 era, technology-enhanced protection of this disease has saved lives in developed countries in which citizens have the privilege of accessing and using such technologies to fight Coronavirus. In the undeveloped countries, on the other hand, citizens have had no accession or ability to use digital technologies to prevent COVID-19. Having this in front, in the MyShield research project, we aim to address how to teach self-care skills in undeveloped countries in the era of COVID-19 using a mobile low-cost application effectively based on a standard educational model (ADDIE). This paper reports a framework that arises from the results of semi-structured interviews and online workshops conducted in the ADDIE design process for the self-care mobile application. The specialists contributed to indicte the appropriate content for teaching self-care skills while informants contributed to optimize the user experience flow.
\end{abstract}

Keywords. Self-care, COVID-19, Mobile Application, Undeveloped Countries.

\section{Introduction}

In the early days of the Coronavirus epidemic, developed and high-income countries used digital technologies (e.g. Contact tracing, IoT, Big-data analytics, and AI) to fight the COVID-19 pandemic [1]. Singapore used an AI Chatbot, Hong Kong and South Korea used contact tracing technology, Canada and Australia used (COVID Alert app) and (COVIDSafe app) respectively to prevent and inform citizens about COVID-19 [13]. Undeveloped countries, on the other hand, are quasi unable to create or use digital technology to prevent and fight the pandemic COVID-19. Moreover, undeveloped countries in the COVID-19 era face more problems and harm than developed countries due to poverty and corruption in the economy, a weak social health system, and an inability to meet self-care requirements [4]. In a 2020 study examining the number of mobile applications available to fight and prevent COVID-19, researchers found that

${ }^{1}$ Corresponding Author, Mohammad HASSANZADHH, Department of Knowledge and Information Science, Tarbiat Modares University, Tehran, Iran. E-mail: hasanzadeh@modares.ac.ir 
over 25 pertinent applications have been developed in areas such as remote assistance, patients monitoring, current status, and COVID-19 prevention [5]. Nonetheless, none of these applications focuses on training self-care skills in undeveloped countries.

MyShield is a research project that aims to develop a low-cost and high-impact digital technology for undeveloped countries through a standalone mobile application based on the standard educational design method (ADDIE). Our paper presents the results from an early project phase, where the specialists contributed appropriate content for teaching self-care skills while informants contributed to the user experience flow.

In the study, our aim is to answer two questions:

RQ1: In the era of COVID-19, what are the appropriate contents for teaching selfcare skills?

RQ2: How should the features and user experience flow of a mobile application for teaching self-care skills be designed?

\section{Methods}

The MyShield project employs the ADDIE design approach [6] for the mobile application development that is conducted in five phases: 1) Analysis, 2) Design, 3) Development, 4) Implementation, and 5) Evaluation. The project is in an early stage; this paper reports on the first phase, where 5 specialists and 14 informants helped us identify and collect the data required for the mobile application. For the response to the first question, semi-structured interviews were conducted with 5 specialists ( 3 infectious disease specialists and 2 nursing specialists) for achievement on the appropriate content for teaching self-care skills. To answer the second question, we held an online workshop with the presence of informants with the Zoom software. These were (are) experts in the fields of health information technology, medical informatics, user experience designers, and as well as Android mobile application developers. This cohort was enrolled using a call via social networks (Instagram and Facebook) published on 1-20 March 2021. Ultimately, 14 informants responded to our call: 6 females and 8 males. The average age of the informants was 38 years. At the beginning of the online workshop, we introduced the participants to the research and explained the objectives of the MyShield project. In the next step of our online workshop, we asked the informants to explain in detail the requirements, feature list, and user flow of their mobile application user experience. Data was collected through video recordings and comments during the online workshop, which lasted an average of three hours. Qualitative methods were used to analyze and categorize user needs, requirements application, and user experience for the self-care (MyShield) mobile application. In order to display the user experience flow, the Balsamiq Mockups software was used.

The study was conducted obtaining the approval of the Ethics Committee of Tarbiat Modares University, Tehran, Iran (IR.MODARES.REC.1399.142).

\section{Results}

Response to RQ1: As a result of the interviews with specialists, the following outcomes were reached: In the application, standard and scientifically accepted contents should be considered. As a result, the application must be easily updated so that users can obtain any useful and valuable content in the subject area of COVID-19 self-care without 
interruption. Specialists agreed that the application would be better if covering the following topics: motivating yourself, daily life management, personal hygiene, healthy eating, and exercise. Self-motivation content needs to teach users how to think positively, motivate themselves, and utilize their intrinsic motivations. Even in these matters, spirituality motivation can be used. In matters related to daily life, the teaching of strategies for stress, fear, and anger management must be considered. Education is also essential in other areas, such as managing life during personal quarantine and social activities. Personal hygiene can include education about masking and observing social distance, washing hands, and knowing how to employ disinfectants. Educating people about healthy eating should include these topics: useful supplements, beverages, fatty foods, proteins, dairy products, nutrition programs, and smoking. The topics that are covered in exercise education include exercising at home, conditions for exercising outdoors, professional exercise, intensity of exercise and, exercise in self-quarantine.

Response to RQ2: Informants agreed on the following flow of features of the mobile application (MyShield): start the application with a splash screen. After that, the registration screen should appear. Registration should be quick and easy, and the user should be asked for only a few pieces of information (i.e. E-mail, user name, and password). Following that, the intro slider should be displayed on the first launch of the application. It is better to introduce the application in at least 3 slides. After the introduction slider, the showcase feature should appear for users to become familiar with the application. Following these screens, the user should be presented with the main menu. The main menu can use two action bars. One at the top of the page displaying the search features of the entire application and the other at the bottom of the page containing buttons, messages, help, settings, and profiles. Additionally, the hamburger button can be made visible in the left-hand corner of the screen. Tapping on it should display the application settings. The settings screen should include features i.e. font setting, title search, clean checkmark, find, last read, dark them, notification, changing password, and about us. Educational content must be button shared and checked marked. Content should also be able to be liked or disliked by the user.

Figure 1 shows the user experience flow using Balsamiq Mockups software.

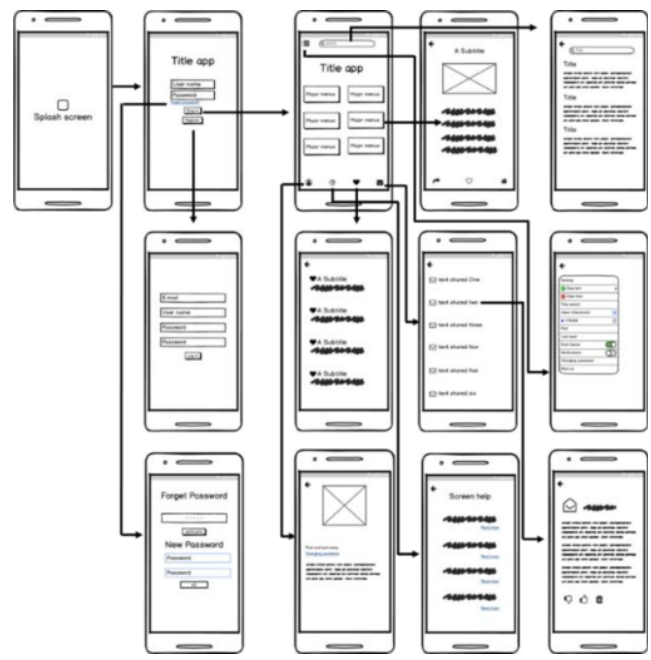

Figure 1. User experience mobile application self-care flow. 


\section{Discussion}

Five specialists and fourteen informants participated in this study with the aim of responding to two research questions (RQs) which are parts of the first phase of the MyShield project (Analysis phase). On RQ1: According to the specialists, the main educational menus are five topics (motivating yourself, daily life management, personal hygiene, healthy eating, and exercise). The importance of managing stress and fear in the face of COVID-19 has been emphasized in other studies [7]. In addition, maintaining a healthy diet and regular exercise can greatly enhance the immune system's ability to fight against COVID-19 [8]. The content expressed by specialists is of great importance for use in the application and has been incorporated in most self-care research related to the COVID-19 era [9]. On RQ2: The informants in the online workshop helped us to draw the user experience flow and features of the application (MyShield). During the COVID19 Pandemic, users will find m-Health applications of better acceptability if they are designed with an effective user interface and based on user experience [10]. Some limitation to this study is the small number of informants. Nevertheless, it was determined that the participants substantially represented the intended user group of the mobile application. Future research can address with a more number of informants.

\section{Conclusion}

We are pleased that interviews with specialists provided us with titles and content for the application, while the online workshop with informants led to a pertinent final version of the application user experience flow for MyShield.

\section{References}

[1] Ting DSW, Carin L, Dzau V, Wong TY. Digital technology and COVID-19. Nature medicine. 2020;26(4):459-61.

[2] Gómez-Ramírez O, Medeiros P, Wainer R, Iyamu I. 13 Does the 'Canada COVID-19 alert'app stand up to critical scrutiny? A rapid qualitative assessment. British Medical Journal Publishing Group; 2021.

[3] Abbas R, Michael K. COVID-19 contact trace app deployments: learnings from Australia and Singapore. IEEE Consumer Electronics Magazine. 2020;9(5):65-70.

[4] Dahab M, Van Zandvoort K, Flasche S, Warsame A, Ratnayake R, Favas C, et al. COVID-19 control in low-income settings and displaced populations: what can realistically be done? Conflict and health. 2020;14(1):1-6.

[5] Islam MN, Islam I, Munim KM, Islam AN. A review on the mobile applications developed for COVID19: an exploratory analysis. IEEE Access. 2020;8:145601-10.

[6] Branch RM. Instructional design: The ADDIE approach: Springer Science \& Business Media; 2009.

[7] Hagger MS, Keech JJ, Hamilton K. Managing stress during the coronavirus disease 2019 pandemic and beyond: Reappraisal and mindset approaches. Stress and Health. 2020.

[8] Sidor A, Rzymski P. Dietary choices and habits during COVID-19 lockdown: experience from Poland. Nutrients. 2020;12(6):1657.

[9] Saeidnia H, Mohammadzadeh Z, Saeidnia M, Mahmoodzadeh A, Ghorbani N, Hasanzadeh M. Identifying Requirements of a Self-care System on smartphones for preventing coronavirus disease 2019 (COVID19). Iranian Journal of Medical Microbiology. 2020;14(3):241-6.

[10] Saeidnia HR, Mohammadzadeh Z, Hassanzadeh M. Evaluation of Mobile Phone Healthcare Applications During the Covid-19 Pandemic. Studies in health technology and informatics. 2021;281:1100-1. 